\title{
DYNAMICS OF CHERNOZEM MICROBIAL COMMUNITY DURING BIODEGRADATION OF CELLULOSE AND BARLEY STRAW
}

\section{E.L. CHIRAK' ${ }^{1}$, O.V. ORLOVA1, T.S. AKSENOVA1, A.A. KICHKO'1, E.R. CHIRAK1, N.A. PROVOROV1, E.E. ANDRONOV1, 2, 3}

\begin{abstract}
${ }^{1}$ All-Russian Research Institute for Agricultural Microbiology, Federal Agency of Scientific Organizations, 3, sh. Podbel'skogo, St. Petersburg, 196608 Russia, e-mail biologartillerist@gmail.com, arriam2008@yandex.ru (corresponding authors);

${ }_{2}^{2}$ Saint-Petersburg State University, 7-9 Universitetskaya nab., St. Petersburg, 199034 Russia;

${ }^{3}$ V.V. Dokuchaev Soil Science Institute, 7/2, Pyzhevskii per., Moscow, 397463 Russia ORCID:

Chirak E.L. orcid.org/0000-0001-9167-5000

Orlova O.V. orcid.org/0000-0002-2154-503X

Aksenova T.S. orcid.org/0000-0002-0002-9538

Chirak E.R. orcid.org/0000-0002-1610-8935

Kichko A.A. orcid.org/0000-0002-8482-6226

Provorov N.A. orcid.org/0000-0001-9091-9384

The authors declare no conflict of interests

Acknowledgements:

Soil sampling and chemical analyzes of soils and substrates (cellulose and straw) were supported financially by the Program of Basic Research of the Presidium of the Russian Academy of Sciences. DNA study (isolation, sequencing and bioinformatic analysis) was supported by Russian Science Foundation (grant № 14-26-00094)

Received June 14, 2016

Andronov E.E. orcid.org/0000-0002-5204-262X
\end{abstract}

\begin{abstract}
Study of cellulose decomposition is an extremely important for the agricultural sciences, as straw is one of the most affordable organic fertilizers. In this area, a large number of research works devoted to biochemical mechanisms of cellulose destruction, as well as study of the cellulolytic microorganisms' taxonomic diversity were conducted. However, the composition of the microbial community was estimated only by the methods based on cultivation and thus describing only a very small part of the soil microbiome. With the advent of «new generation sequencing» methods the analysis of whole microbial communities found in the soil became possible. The main objective of this work was the implementation of an integrated approach, combining agrochemical techniques of biodegradation processes intensity estimation with modern molecular methods (soil metagenome analysis of 16S rRNA) in the process of cellulose decomposition in two substrates (straw and filter paper). It was first shown by the method of high-throughput sequencing that the introduction of a straw in soil caused dipper changes in the structure of the microbial community than the introduction of chemically pure cellulose. The model experiment was carried out on typical chernozem, sampled in the Voronezh region in fallow areas from a depth of 2-15 cm. Chemically pure cellulose (very fine-chopped filter paper) and crushed straw of barley were added at $1 \mathrm{~g}$ per $100 \mathrm{~g}$ of soil. Analyzes were performed on days $0,7,14,21$ and $28 . \mathrm{CO}_{2}$ emission, the content of nitrates, ammonium nitrogen, labile carbon, and microbial biomass were estimated. During the first 7 days, microbial mass and respiration increased when straw was added. For cellulose, an increase in biomass was not significant, and respiration was activated with a delay. The introduction of cellulose and straw reduced the soil level of nitrate nitrogen compared to control, and with straw, the indicator lowered to a lesser extent. In this work, some taxa were found, the proportion of which increased (Chthoniobacteraceae, Xanthomonadaceae, Chitinophagaceae), and decreased (Gaiellaceae). Among the microorganisms whose proportion increased after the introduction of cellulose, we found classic cellulose destructors (Chitinophaga and representatives of the families Streptosporangiaceae and Micromonosporaceae), and microorganisms whose ability to decompose cellulose had not previously been reported yet (Chthoniobacter, Chitinophaga). Community homeostasis was found (i.e. significant changes in the composition of microbiome on day 14 of the experiment returned to the original state on day 28). Agrochemical analysis (dynamics of nitrate nitrogen content, the rate of release of carbon dioxide, dynamics of bacterial biomass) fully agreed with the analysis of metagenomic data in fact that the microbial community actively respond to the introduction of straw as opposed to the introduction of pure cellulose.
\end{abstract}

Keywords: microbiome, soil, metagenome, straw, cellulose, biodegradation 
chemical functions of soil microorganisms. Global climate changes directly affecting the temperature and water regimes alongside with increasing humaninduced adverse impact may change significantly the biodegradation tendency and intensity for organic substrates. A hypothesis of that a final result of substrate destruction depends not only on its chemical composition but also on a structure of destructing microbial community gains increasingly strong confirmations. However, regularities of biodiversity formation and microbial community functioning during the straw decomposition remain unstudied [1]. It is particularly associated with the multifunctionality of microorganisms, i.e. changes in the microbial community structure do not necessarily depend on a type of substrate applied [2].

One of the most important components of plant residues, including those by their weight, is cellulose. Straw is one of the most affordable crop residues in agriculture, which are recommended to be left on fields and added to soil. It is considered a good resource for humus accumulation. According to different sources, its isohumic coefficient equals to $0.10-0.25$, i.e. leaving of $2-4 \mathrm{t}$ of straw causes the formation of $0.2-1.0 \mathrm{t}$ of humus per 1 ha [3]. We have assumed that pure cellulose and straw will be decomposed in different ways due to their chemical peculiarities. Straw consists of $90 \%$ of fiber, which is composed of 35-45\% of cellulose, 14-20\% of lignin, 20-30\% of pentosans, 2-3\% of kutin, and 3-5 \% of silica salts [3]. As a consequence, the destruction of different substrates will involve different microorganisms, first of all, cellulosedecomposing ones, that is of real practical and academic interest $[4,5]$.

The study of a microbial community when adding straw and pure cellulose in soil by molecular methods will enable to better demonstrate a role of the functional structure of the community, trace its relationship with a taxonomic composition, space-time variability of the mentioned indicators, and agrochemical parameters of soil. This approach will make it possible to establish a probable role of microorganisms which are not taken into account by traditional methods. It is also interesting to consider differences in the taxonomic composition of microbial communities that decompose straw and pure cellulose over time, and compare microbiomes formed by the end of the process.

It was first shown by the high-throughput sequencing method that the introduction of straw in soil caused deeper changes in the structure of the microbial community than the introduction of chemically pure cellulose.

The objective of the work was to implement an integrated approach that combines conventional biochemical techniques for estimation of intensity of biodegradation processes with modern molecular methods in order to study microbial communities decomposing two cellulose-containing substrates (straw and filter paper) over time.

Technique. In a model experiment, chemically pure cellulose (as a very fine-chopped filter paper) and shredded straw of barley (ash 7.6 \%, $\mathrm{N}_{\text {total }} 1.95 \%$, $\mathrm{P}_{\text {total }} 1.1 \%, \mathrm{~K}_{\text {total }} 2.47 \%$ ) were added to typical chernozem sampled in Voronezh region (Kamennaya Steppe conservation area, $51^{\circ} 01^{\prime} 41.6^{\prime \prime} \mathrm{N}, 40^{\circ} 43^{\prime} 39.3^{\prime \prime} \mathrm{E}$ ) in fallow areas from a depth of $2-15 \mathrm{~cm}\left(\mathrm{C}_{\text {total }} 4.48 \pm 0.06 \%, \mathrm{C}_{\text {humus }} 4.37 \pm 0.05 \%\right.$, $\mathrm{N}_{\text {total }} 0.394 \pm 0.002 \%, \mathrm{pH}_{\text {water }} 6.31 \pm 0.01, \mathrm{pH}_{\text {salt }} 7.35 \pm 0.0$, total exchangeable bases $44.17 \pm 0.43 \mathrm{mg}$-equ/100 g, labile phosphorus and potassium content according to Machigin $67.5 \pm 8.0$ and $12.6 \pm 0.8 \mathrm{mg} / 100 \mathrm{~g})$. Soil without any cellulose-containing substrates added was used as a control.

The substrate was added at $1 \mathrm{~g}$ per $100 \mathrm{~g}$ of soil. The experiment was carried out in Petri dishes, in 5 replicates for a period of the experiment, and 7 replicates for the last measurement. Dry soil $(50 \mathrm{~g})$ was placed into each dish and $30 \mathrm{~g}$ of dry soil was places into each $500 \mathrm{ml}$ vial (to measure carbon dioxide 
emissions, in 5 replicates). The soil was wetted up to $50 \%$ of the full field moisture capacity, placed under a glass dome together with a water container in order to maintain the constant humidity level and incubated in a dark room at 23$25{ }^{\circ} \mathrm{C}$. $\mathrm{CO}_{2}$ emission, contents of nitrates, ammonium nitrogen, labile carbon, microbial biomass were estimated on the day when the substrate were introduced (day 0 ), as well as on days $7,14,21$ and 28. The taxonomic structure of a microbiome was identified based on the total DNA analysis. All the data was obtained for a mixed sample, in 3-5 replicates.

Agrochemical soil analyses were conducted by generally accepted methods [6]. Content of labile carbon in an extract, according to Shults [7], was identified using Ultraspec spectrophotometer (LKB, Sweden; $\lambda=340 \mathrm{~nm}$ ) [8]. Soil respiration was measured by Tsvet gas chromatograph (ZAO Tsvet, Russia) equipped with a thermal-conductivity detector and using helium as a carrier gas. Microbial biomass in soil was measured by the substrate-induced respiration method [9], with identifying the total biomass and fungal biomass (treatment with streptomycin and rifampicin, $16 \mathrm{mg}$ of antibiotic per $1 \mathrm{~g}$ of soil).

DNA was extracted from $0.5 \mathrm{~g}$ of soil in 3 replicates for each time period (a total of 45 samples). The samples were exposed to mechanical breakdown for $1 \mathrm{~min}$ in an extraction buffer with glass beads at the maximum power in Precellys apparatus (Bertin Technologies, France). The extraction buffer consisted of $350 \mu \mathrm{l}$ of solution A $(200 \mathrm{mM}$ sodium phosphate buffer, $240 \mathrm{mM}$ guanidine isothyocyanate; $\mathrm{pH} 7.0), 350 \mu$ of solution $\mathrm{B}(500 \mathrm{mM}$ Tris- $\mathrm{HCl}, 1 \%$ SDS, $\mathrm{w} / \mathrm{v} ; \mathrm{pH} 7.0), 400 \mu \mathrm{l}$ of phenol:chloroform mixture (1:1). The preparation was centrifuged at the maximum speed for $5 \mathrm{~min}$. Then, the aqueous phase was sampled and the re-extraction with chloroform was conducted. DNA was precipitated by adding an equal volume of isopropyl alcohol. After centrifugation, the precipitate was washed by $70 \%$ ethanol and dissolved in water at $65{ }^{\circ} \mathrm{C}$ for 5-10 min. It was purified by $1 \%$ agarose gel electrophoresis with further DNA extraction from the gel by silicon oxide sorption method $[10,11]$.

The purified DNA preparation (10-15 ng) was used as a matrix for the PCR $\left(30 \mathrm{~s}\right.$ at $95{ }^{\circ} \mathrm{C}, 30 \mathrm{~s}$ at $50{ }^{\circ} \mathrm{C}, 30 \mathrm{~s}$ at $72{ }^{\circ} \mathrm{C}$; a total of 30 cycles) with applying Encyclo polymerase (Evrogen, Russia) and universal primers to variable region V4 of 16S rRNA gene: F515 (5'-GTGCCAGCMGCCGCGGTAA) and R806 (5'-GGACTACVSGGGTATCTAAT) [12]. Besides, oligonucleotide identifiers for each sample and auxiliary sequences required for pyrosequencing as per Roche protocol (Switzerland) were introduced in primers. Sample preparation and sequencing was carried out in GS Junior apparatus (Roche, Switzerland) in accordance with the manufacturer's recommendations.

The resulting sequences were analyzed in QIIME 1.8.0 [13]. Libraries were classified by identifiers, sequencing quality was checked and nucleotide sequences were filtered, sequences were combined into operational taxonomic units (OTU, analogue of species) by de novo method based on $97 \%$ threshold of similarity of genes $16 \mathrm{~S}$ rRNA [14], representative sequences were sampled (one from each OTU), representative nucleotide sequences were aligned by Uclust method, matrix of genetic distances and phylogenetic tree were constructed by Fasttree method. The sequences presented in all samples less than twice as well as those belonging to chloroplasts were deleted from the data obtained. Taxonomic identification of OTUs was carried out using RDP algorithm (http://rdp.cme.msu.edu/) and Greengenes data bank [15].

Based on the table of OTU representation in samples, Shannon's biodiversity indices (ChaoI) were calculated: $S_{\text {est }}(\mathrm{ChaoI})=\mathrm{S}_{\mathrm{obs}}+\mathrm{a}^{2} / 2 \mathrm{~b}$, where, $\mathrm{S}_{\text {est }}$ is the estimated number of OTUs; $\mathrm{S}_{\text {obs }}$ is the observed number of OTUs; $a$ is the number of OTUs found once; $b$ is the number of OTUs found twice. Moreover, 
cumulative curves that characterize the OTU number expansion over time depending on the quantity of sequences experienced sequencing have been plotted. Statistical processing was carried out in QIIME (http://qiime.org/). In recording the bacterial biomass, nitrate nitrogen content in soil and $\mathrm{CO}_{2}$ emission, the mean values and standard errors of mean $( \pm$ SEM) were calculated. Significance of differences was estimated by the Student's $t$-test (significance level $\mathrm{p}<0.05$ ).

Results. One of the parameters reflecting an increment in microbiological activity of soil during the destruction of complex organic compounds is an amount of bacterial biomass. The maximum biomass was registered after the straw had been added to soil (Fig. 1, A). The total bacterial biomass accumulated after introduction of cellulose in soil showed no statistical difference from the control. The reason for this was probably a lack of nitrogen accessible for microorganisms as there was no nitrogen in the chemically pure cellulose, while in the straw it was present with carbon at the ratio of $\mathrm{C}: \mathrm{N}=23.7$. In addition, the tested straw contained a considerable amount of labile organic substances that resulted in the increase of their proportion in soil by $40 \%$ as compared to the control.

A
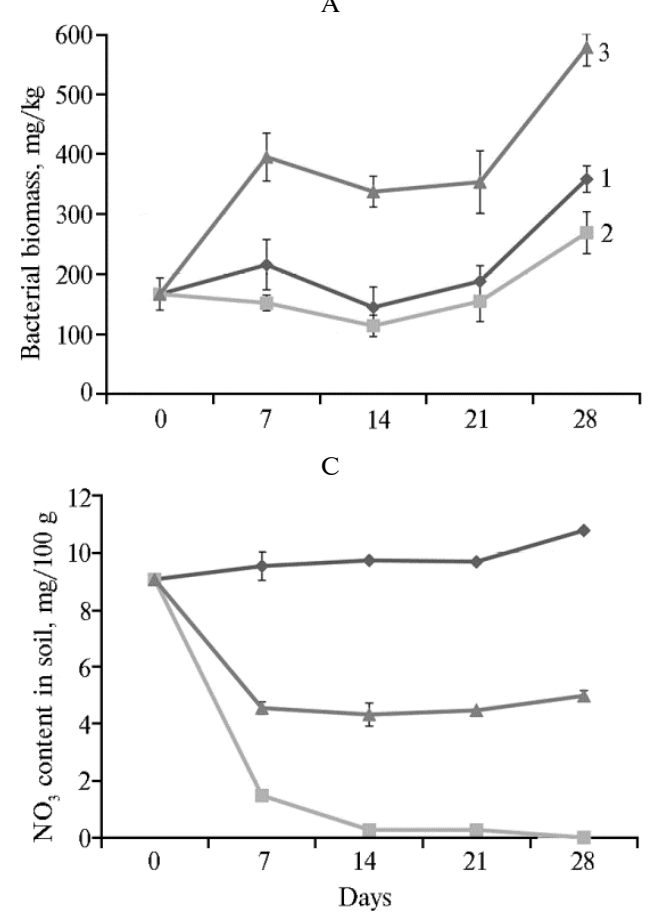

B

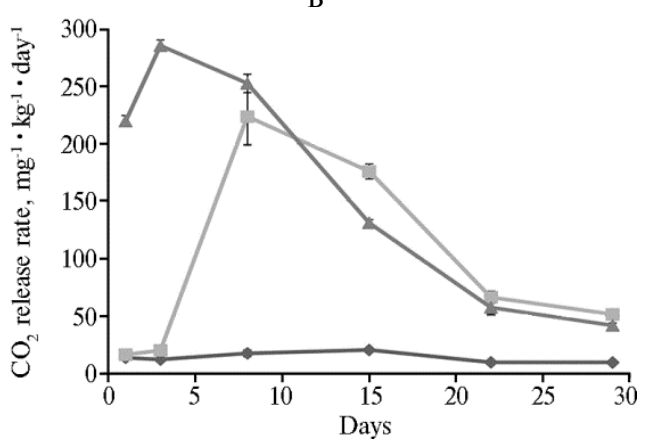

Fig. 1. Dynamics of bacterial biomass (A), carbon dioxide release rate (respiration) $(\mathrm{B})$ and nitrate nitrogen content in soil $(C)$ in the model experiment of different substrate decomposition: 1 control (soil without any substrates added), 2 cellulose, 3 - straw. Soil - typical chernozem. Errors of mean provided.

Assessment of the amount of $\mathrm{CO}_{2}$ released has shown that biological processes after introduction of straw were the most intensive for the first 3 days (see Figure 1, B) due to the use of water-soluble organic compounds that is consistent with the literature data [16]. For cellulose, there was a delay in activation of microorganisms followed by carbon dioxide emission (lag-phase was observed) [17, 18]. Starting from day 8 , the intensity of carbon dioxide release from soil decreased.

The introduction of cellulose and straw decreased the content of nitrate nitrogen in soil as compared to the control (see Fig. 1, C), and the decrease for straw was lesser than for pure cellulose. It is explained by the already mentioned absence of nitrogen in the filter paper that causes the immobilization of mineral nitrogen from soil during the decomposition process [3]. For straw, the substrate was decomposed with the use of nitrogen contained both in soil and the substrate itself.

Our data obtained by conventional methods are consistent to each other. During the first 7 days we observed the gain in biomass and activation of respire- 

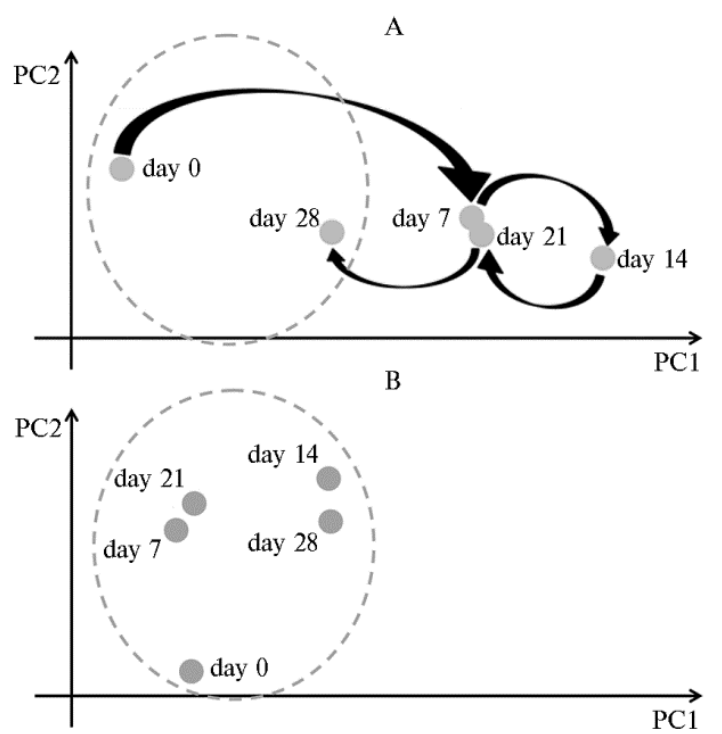

Fig. 2. Results of the similarity analysis of microbial communities ( $\beta$-diversity analysis) by the principal component method (PC) when introducing straw (A) and cellulose $(B)$ in soil (model experiment, typical chernozem soil). Samples averaged for replicates (3 replicates for each day) are ringed. Locations of control samples (soil without substrates introduced) are dotted. tion processes related thereto when the straw was added. For cellulose, there was no significant gain in biomass, and the respiration intensified with delay. It may be assumed that the straw as a substrate has stimulated a considerable part of the bacterial community, including R-strategists which actively utilize easily-accessible nutrients from plant residues [18]. Cellulose has activated a small number of microorganisms specialized only in the destruction of this substrate. The observed dynamics of amounts of nitrogen-containing compounds was associated with that soluble forms of nitrogen in the experiments with cellulose-containing substrates were involved in the biodegradation of the latter. Since the straw contains organic nitrogen in itself, bacteria will, first of all, consume this nitrogen.

As a result of sequencing DNA extracted from soil, 87,563 sequences belonging to 408 OTUs have been obtained. There were OTUs from 22 bacterial phyla and 1 archaea phyla, as well as 265 procaryotic families. Biodiversity of the bacterial community in soil remained unchanged irrespective of the substrate introduced (indices of Shannon and ChaoI varied within 7.4-6.9 and 611-528, respectively).

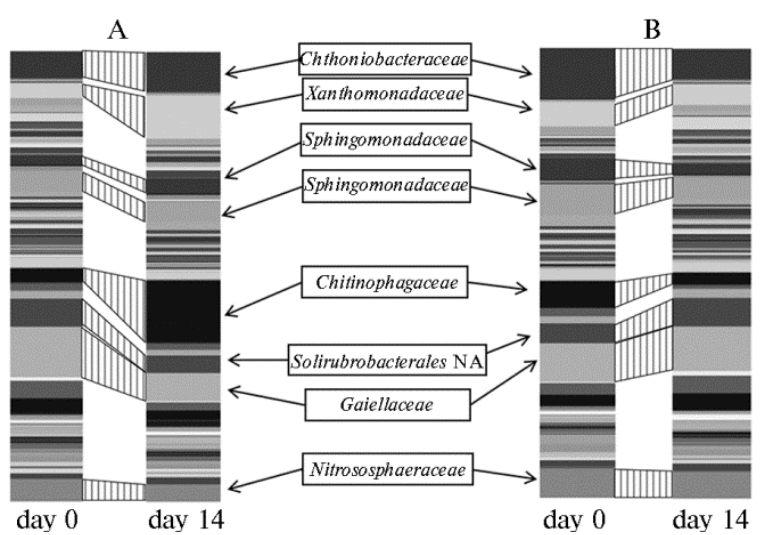

Fig. 3. Bacterial community composition in soil on day 0 and day 14 of the experiment when introducing straw (A) and cellulose (B) (model experiment, typical chernozem soil).
Straw added to soil had greater impact on the bacterial community composition than the filter paper did. According to the high throughput sequencing and the agrochemical analysis, the most significant changes in the community composition were observed on day 14 with its further recovery to the original state (control, Fig. 2) that was indicative of the community homeostasis, the maintenance of which resulted in the original structure recovery in the decomposition processes of cellulose-containing substrates. It should be noted that bacteria families was found whose proportion in the community either decreased (Gaiellaceae) or increased (Chthoniobacteraceae, Xanthomonadaceae, Chitinophagaceae) (Fig. 3). On the plot constructed by the principal component method for the cellulose introduction, all the samples (irrespective of sampling 
time) were close to the control ones. Hence, cellulose had a slight impact on the microbial community in soil at initial biodegradation stages.

On day 28 of the experiment with straw, we observed a significant increase in a number of bacteria (88 times as much in some cases) belonging to genus Chitinophaga, families Streptosporangiaceae and Micromonosporaceae (Fig. 4). According to the present-day data, representatives of these taxa are able to destroy cellulose [19-21]. On day 28 after introducing the filter paper in soil, an increase in abundance of bacteria of families Promicromonospora and Devosia was registered (Fig. 4). They also can produce cellulosolytic enzymes [22, 23]. Only one OTU has been revealed there, its number increased both for the straw and for filter paper. This OTU belonged to genus Chthoniobacter phylum Verrucomicrobia. Bacteria of the phylum are understudied yet (one cultivated representative), therefore, there is no data of their ability for cellulose decomposition [24]. All the found archaea belonged to genus Nitrososphaersceae widely spread in soils of Russia [25]. However, this OTU showed no significant dynamics throughout the experiment (see Fig. 2).
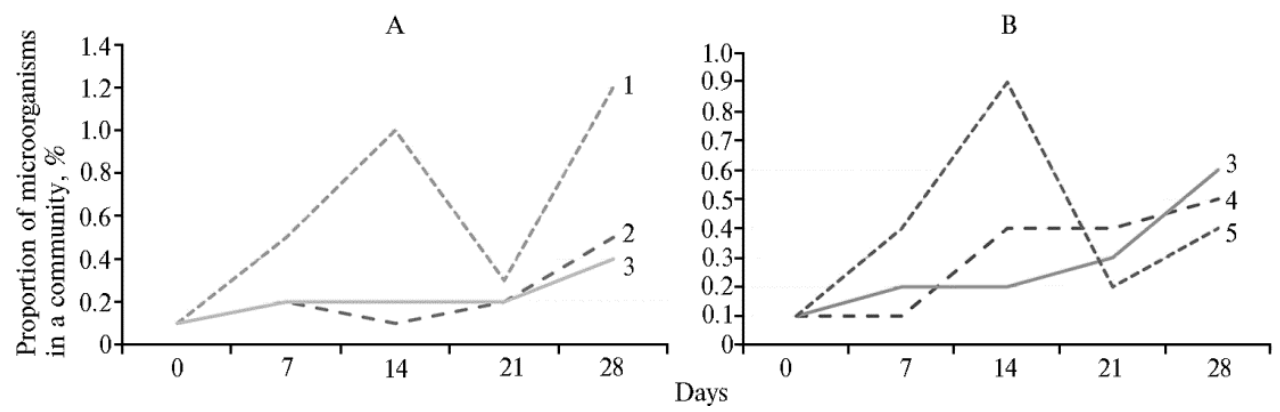

Fig. 4. Dynamics in number of bacteria of Streptosporangiaceae (1) and Micromonosporaceae families (2) and genera Chtoniobacter (3), Promicromonospora (4), Devosia (5) when introducing straw (A) and cellulose (B) in soil (model experiment, typical chernozem soil).

As we are the first who applied the metagenomic analysis of gene $16 \mathrm{~S}$ rRNA, it is difficult to compare the data obtained with any results of other works. The most authors studied the species identity of cellulosolytics revealed [26-28], while we used taxonomic units. The data obtained earlier has been confirmed in our study on the basis of higher taxonomic ranks (families and orders), as the majority of works indicate that actinobacteria are actively involved in the cellulose decomposition. However, we have also identified OTUs belonging to genera whose ability to decompose cellulose in soil had not been reported yet (Chthoniobacter, Chitinophaga).

It should also be noted that all the regularities revealed have been tested only for the soil concerned (typical chernozem) and are subject to confirmation for other types of soils (sod-podzolic, grey forest soil, etc.). Further study of cellulose decomposition processes in soil will be associated with an analysis of cellulose hydrolysis enzyme system which is represented in soil bacteria by complex aggregates of proteins that can break $\beta$-1,4-glucosidic bonds inside of a cellulose molecule (endoglucanase), from the reducing and nonreducing ends (cellobiohydrolase), as well as in the glucose dimer cellobiose (cellobiase). Molecular genetic testing of microorganisms (including genomic sequencing) responsible for the destruction of cellulose-containing substrates is required as well.

Thus, we have obtained similar results using both conventional agrochemical methods and high throughput sequencing. The decomposition of the straw added to soil involved a considerable part of the bacterial community as this substrate was more well-balanced in the composition of primary biogenic elements and more natural for the soil. As a result, we observed the increased 
respiration of microorganisms, gain in their biomass through day 14 and further reduction in these parameters by day 28. Only a small part of the bacterial community appeared to be able to destruct pure cellulose, no significant differences in the composition of microbial communities for this variant over time were revealed. The obtained data on changes in a microbiome after introducing the straw and chemically pure cellulose may serve as a basis for developing predicative dynamics models for microbiomes during the organic substance decomposition process depending on a type of substrate to be decomposed and physicochemical properties of soil. Predicative models to be developed in future will allow studying relationships between the taxonomic and functional structures of the soil microbiome, as well as improving the composition of microbial preparations and their application methods.

\section{REFERENCES}

1. Nannipieri P., Ascher J., Ceccherini M.T., Landi L., Piet ra me 11 a ra G., Re nella G. Microbial diversity and soil functions. Eur. J. Soil Sci., 2003, 54(4): 655-670 (doi: 10.1046/j.1351-0754.2003.0556.x).

2. M a r s chner M., Middlestead P., Clark I.D. Using a simple high-performance liquid chromatography separation and fraction collection methodology to achieve compoundspecific isotopic analysis for dissolved organic compounds. Rapid Commun. Mass Sp., 2005, 19(2): 2610269 (doi: 10.1002/rcm.1780).

3. M i n e e v V.G. Agrokhimiya [Agrochemistry]. Moscow, 2004 (in Russ.).

4. H a ls a 11 D.M., G i bs o n A.H. Cellulose decomposition and associated nitrogen fixation by mixed cultures of Cellulomonas gelida and Azospirillum species or Bacillus macerans. Appl. Environ. Microb., 1985, 50(4): 1021-1026.

5. To m m e P., W a r re n R.A.J., Gilkes N. Cellulose hydrolysis by bacteria and fungi. $A d v$. Microb. Physiol., 1995, 37: 1-81 (doi: 10.1016/S0065-2911(08)60143-5).

6. Poll C., Marhan S., Ingwerse n J., Kand e le r E. Dynamics of litter carbon turnover and microbial abundance in a rye detritusphere. Soil Biol. Biochem., 2008, 40: 1306-1321 (doi: 10.1016/j.soilbio.2007.04.002).

7. Shul'ts E., Ke rshens M. Pochvovedenie, 1998, 7: 890-894 (in Russ.).

8. Panikov N.S., Go rbe nko A.Yu., Svetlov S.V. Sposob opredeleniya summarnogo soderzhaniya vodorastvorimykh organicheskikh veshchestv $v$ pochve. A.C. № 3949440/30-15. Opubl. 1987. Byul. № 23 [Assay of total water-soluble organic compounds in soils. A.C. SU № 3949440/30-15. Publ. 1987. Bul. No 23] (in Russ.).

9. West A.W., S parling G.P. Modification to the substrate-induced respiration method to permit measurement of microbial biomass in soils of different water contents. J. Microbiol. Meth., 1986, 5: 177-189 (doi: 10.1016/0167-7012(86)90012-6).

10. Diaferia G., Saltini G., del Vecchio E., Rossi-Bernardi L., Biunno I., Malferrati G., Monferinin P., De Blasio P. High-quality genomic DNA from Human whole blood and mononuclear cells. BioTechniques, 2002, 33(6): 1128-1130.

11. Andronov E.E., Petrova S.N., Chizhevskaya E.P., Korostik E.V., Akh t e m o va G.A., P i n a e v A.G. Mikrobiologiya, 2009, 78(4): 525-534 (in Russ.).

12. B at es S.T., B erg-Lyons J.G., Caporaso W.A., Walt e rs W.A., Knight R., $\mathrm{F}$ i e r e $\mathrm{r}$ N. Examining the global distribution of dominant archaeal populations in soil. ISME J., 2010, 5: 908-917 (doi: 10.1038/ismej.2010.171).

13. Caporaso J.G., Kuczynski J., Stombaugh J., B ittinger K., Bush man F.D., Coste 11 o E.K., Huttley G.A. QIIME allows analysis of high-throughput community sequencing data. Nat. Methods, 2010, 7(5): 335-336 (doi: 10.1038/nmeth.f.303).

14. Edga r R.C. Search and clustering orders of magnitude faster than BLAST. Bioinformatics, 2010, 26: 2460-2461 (doi: 10.1093/bioinformatics/btq461).

15. De S a n t is T.Z., Hugenholtz P., Larsen N., Rojas M., B rodie E.L., Ke 1le r K., A nde rse n G.L. Green genes, a chimera-checked 16S rRNA gene database and workbench compatible with ARB. Appl. Environ. Microbiol., 2006, 72: 5069-5072 (doi: 10.1128/AEM.03006-05).

16. M is husti n E.N. Ispol'zovanie solomy kak organicheskogo udobreniya [Straw as an organic fertilizer]. Moscow, 1980 (in Russ.).

17. Panik ov N.S., A fre mova V.D., A s e e va I.V. Pochvovedenie, 1984, 1: 56-62 (in Russ.).

18. Kozhevin P.A. Mikrobnye populyatsii v prirode [Natural microbial populations]. Moscow, 1989.

19. Chung E.J., Park T.S., J e o n C.O., Chung Y.R. Chitinophaga oryziterrae sp. nov., isolated from the rhizosphere soil of rice (Oryza sativa L.). Int. J. Syst. Evol. Microbiol., 2012, 112: 
345-351 (doi: 10.1099/ijs.0.036442-0).

20. Z hang L.P., J i a g C.L., C h e n W.X. Streptosporangium yunnanense sp. nov. and Streptosporangium purpuratum sp. nov., from soil in China. Int. J. Syst. Evol. Microbiol., 2005, 55: 719724 (doi: 10.1099/ijs.0.02565-0).

21. De Menezes A.B., M c Donald J.E., Allison H.E., Mc Carthy A.J. Importance of Micromonospora spp. as colonizers of cellulose in freshwater lakes as demonstrated by quantitative reverse transcriptase PCR of 16S rRNA. Appl. Environ. Microbiol., 2012, 78(9): 495-505 (doi: 10.1128/AEM.07314-11).

22. Cazemier A.E., Verdoes J.C., Reubsaet F.A., H a ckste in J.H., va n d e r D rift C., D e n C a m p H.J.O. Promicromonospora pachnodae sp. nov., a member of the (hemi)cellulolytic hindgut flora of larvae of the scarab beetle Pachnoda marginata. Antonie Van Leeuwenhoek, 2003, 83(2): 135-148 (doi: 10.1023/A:1023325817663).

23. Y o o S.H., W e o $n$ H.Y., K i m B.Y., Hong S.B., K w o n S.W., C ho Y.H., S t a c k e b randt E. Devosia soli sp. nov., isolated from greenhouse soil in Korea. International Journal of Systematic and Evolutionary Microbiology, 2006, 56: 2689-2692 (doi: 10.1099/ijs.0.64214-0).

24. S a ngwa n P., C h e $\mathrm{n}$ X., $\mathrm{Hug}$ e $\mathrm{n}$ holt z P., J a n s s e $\mathrm{n}$ P.H. Chthoniobacter flavus gen. nov., sp. nov., the first pure-culture representative of subdivision two, Spartobacteria classis nov., of the phylum Verrucomicrobia. Appl. Environ. Microbiol., 2004, 70(10): 5875-5881 (doi: 10.1128/AEM.70.10.5875-5881.2004).

25. Chirak E.L., Pershina E.V., Dol'nik A.S., Kutovaya O.V., Vasilenko E.S., Kogut B.M., Merzlyakova Ya.V., Andronov E.E. Taxonomic structure of microbial association in different soils investigated by high-throughput sequencing of 16S-rRNA gene library. Agricultural Biology, 2013, 3: 100-109 (doi: 10.15389/agrobiology.2013.3.10eng).

26. Eichorst S.A., Kuske C.R. Identification of cellulose-responsive bacterial and fungal communities in geographically and edaphically different soils by using stable isotope probing. Appl. Environ. Microbiol., 2012, 78(7): 2316-2327 (doi: 10.1128/AEM.07313-11).

27. Vries M., S chöler A., Ertl J., Xu Z., S chloter M. Metagenomic analyses reveal no differences in genes involved in cellulose degradation under different tillage treatments. FEMS Microbiol. Ecol., 2015, 91(7): fiv069 (doi: 10.1093/femsec/fiv069).

28. Hess M., Sczyrba, A., Egan R., Ki m T.W., Chokhawala H., Schroth G., Luo S., Clark D.S., Chen F., Zhang T., M a ckie R. Metagenomic discovery of biomass-degrading genes and genomes from cow rumen. Science, 2011, 331: 463-467 (doi: 10.1126/science. 1200387). 